\title{
Religion and Development: An Exploration of the Basis of Wholistic Education in Universal Basic Education Programme in Nigeria
}

\author{
Kwaji Tizhe Takwate \\ Department of Arts \& Social Sciences Education, Adamawa State University, Mubi \\ Email: taquate85@yahoo.com
}

\begin{abstract}
Universal Basic Education (UBE) programme in Nigeria was launched in 1999, with the goal of providing "free, universal and compulsory basic education for every Nigerian child aged 6-15 years". The scope of UBE among others include the initiation for the acquisition of functional literacy, numeracy and life skill for adults and special programmes of encouragement to all marginalized groups (girls, women, nomads, out-of-school youth and Quranic students). Religion has been destructively criticized largely due to the sufferings and devastating situations humanity has and is passing through over the years in Nigeria and based on these, religion is seen as being pervasive and it continues to weaken the moral fiber of UBE programme implementation. Therefore, any developmental tool that is effective and can drive home development must be such that is particularly viable in tackling the problems of religion. Thus, in a bid to revitalize a society already bedeviled with various degenerating ills, religious education which is wholistic in nature should become everyone's focus. This paper described the importance, the curriculum and technique for teaching wholistic religion education for religious tolerance and sustainable development in UBE. The paper concluded that no known religion is devoid of moral and ethical principles and religion is a force which has mostly influenced the character of mankind. This paper maintained that development can be enriched by the insights offered by religion, faith, spirituality and values. Based on these, the paper recommended that religion should be carried along in making policies, the study of moral education should be made compulsory in all categories of learning and the National Orientation Agency should also include it in their plans and school curriculum should be more of reflective thinking.
\end{abstract}

Keywords: UBE curriculum; wholistic education; girl-child; religious education; transformational education

\section{Introduction}

The Universal Basic Education (UBE) programme in Nigeria was launched in 1999, with the goal of providing "free, universal and compulsory basic education for every Nigerian child aged 6-15 years". Therefore, initially UBE-related activities were carried out only in areas of social mobilization, infrastructural development, provision of instructional materials, etc. The UBE programme only took off effectively with the signing of the UBE Act in April 2004 with children aged 3-5 years, for Early Children Care and Development Education, children aged 6-11 years and above for primary school education and children aged 12-14 years and above for junior secondary school education as the main beneficiaries of the programme. The scope of UBE among others include the initiation for the acquisition of functional literacy, numeracy and life skill for adults and special programmes of encouragement to all marginalized groups (girls, women, nomads, out-of-school youth and Quranic students). 
The roles and contexts of motivational incentives as tools for teachers' effectiveness cannot be In its latest review of Nigeria's educational standing, UNESCO has concluded that although progress has been made in basic education, much more remains to be done in terms of wholistic education of the child both in quantity and quality because participation in primary education is still low in comparison with primary school age population and with factors such as social, cultural barriers that hinders female participation in the programme and lack of enforcement of the UBE Act 2004 on enrolment and retention (Stephen, Jan \& Glenda, 2015).

In our world today, there is one concept that has been greatly blamed for all problems of development we are face. All forms of ills and social vices are attributed to it. It has been blamed for the destruction of the political, socio - economic and cultural life of many societies. It is noted to stunt growth of religion and spiritual development of individuals. It destroys ethical and democratic values, creates political instability and undermines the integrity of a nation. It encourages and promotes crimes and large scale fraud (Aja, Eze \& Eke, 2014). There is hardly any sector of life that is not affected by it. Presently, it is the major challenges to religion and sustainable development.

The concept is religion. Ozioma (2017) observed that with religion being a problem there can be neither meaningful religious practice nor sustainable development. By breeding and feeding on inefficiency, religion invariably destroys a system. In fact, religion is literally the antithesis of development and progress (Obasanjo, 2000).

Thank God for His mercy. Certainly, when a problem becomes identifiable, it makes solution to it easy and attainable. Nigerian government like other governments in the world having known what has and is bedeviling us (like the Maitatsine attack in the 1980s, Kaduna riots, 1990s - 2020s , Zango Kataf crisis in 1992 and the insurgency attacks perpetrated by Boko Haram in 2000s etc) have employed various means to end religion crisis but to no avail through formation of different anti-religion Agencies, Decrees and Acts like The Corrupt Practices Decrees of 1975, War Against Indiscipline (WAI) in 1984, the Code of Conduct Bureau and Tribunal Act of 1990, Independent Corrupt Practices and Other Related Offences Commission (ICPC) in 2000, Economic and Financial Crimes Commission (EFCC) in 2003, Socio-Economic Right and Accountability Project (SERAP) in (2004), King Abdullaziz International Centre for Interreligious and Intercultural Dialogue (KAICIID) in 2012 et al.

Indeed, the phenomenon of religion has become pervasive and continues to weaken the moral fiber of the world. Giving this backdrop, it becomes clearer that religion has been the greatest challenge to religious practices and development in the 21 st century. Any developmental tool that is effective and can drive home development must be such that is particularly viable in tackling the problems of religion. Thus, in a bid to revitalize a society already bedeviled with various degenerating ills, religious education which is wholistic in nature should become everyone's focus.

Wholistic education is an effort to improve the education quality in schools. The actualization of wholistic education is closely linked to the cultural conditioning being established among the school's members. The achievement of wholistic education requires efforts to change the conditions and behaviours of school, school community, and stakeholders. Wholistic education may be a philosophy of education supporting the premise that every person finds identity, meaning, and purpose in life through connections to the 
community, to the natural world, and to humanitarian values such as compassion and peace (Ganesh, 2013). It develops learners' potential harmoniously (integrated and balanced), including intellectual, emotional, physical, social, aesthetic, and spiritual (Miller, 2005).

With these in mind, the responsibility of educators is to create curriculum that can meet the needs of religion in developing people that are morally upright through wholistic education today. So therefore, these three areas - wholistic education, religious education and development are interdependent and are the focus of this paper to discover a model that can work in or outside theological setting. As you join me in exploring this topic, we will break the tradition motif of formal third-person language and engage in personal conversation.

\section{Review of Literature}

\subsection{Religious Education}

Religion may be a system of social unity commonly understood as a gaggle of beliefs or attitudes concerning an object, person, unseen or imaginary creature, or system of thought considered to be supernatural, sacred, divine or highest truth, and therefore the moral codes, practices, values, institutions, and rituals related to such belief or system of thought. It is a structure within which specific theological doctrines and practices are advocated and pursued; usually among a community of like-minded believers. Religion can be concluded to be an institution that shapes the attitude and values of individuals and societies in terms social behaviour, economic activities and political involvement.

Radin in Ikechi-Ekpendu, Audu and Ekpendu (2016) sees religion as one that came to give answer to emotional tension created by puzzling and mystifying environment. If one analyses this statement further, it means that religion came into existence to give answer to the fear environment created during immature stage of man's development. This then means that religion is a thing of the past, and not of present when man is almost in his highest point of his development through the interplay of intellect and will. But Ugwu (1999) quipped that, ".... Religion is - and seems likely to say - an inevitable a part of human life". According to him religion may be a means of tackling the issues of suffering, evil and hostility altogether ages. It is when religion is seen as useful to man that it can then make meaning. Religion can be found in all known human societies and for people to know and get acquainted with its tenancy they need to be educated in its principles.

Religious education as instruction in religion may be a subject of general education. It has been described as an education in a school which places a strong emphasis on the beliefs associated to a particular religion. This paper defines religious education as the act of teaching people, especially students about the tenets, doctrines and values of a religion with the aim of guiding them to imbibe the moral principles and ethical standards which will help them to become well-meaning members of the society. Education is a determinant factor for the development of any nation or society. According to Igwe, Saheed and Olufemi in Ozioma (2017) educational planners and administrators have consistently expressed the view that education is not only a costly venture but also that no nation can rise above the quality of her educated citizenry. Hinging on this, religious education is one among the three known methods by which individuals may seek to solve the world's problems. The opposite two are revolution and war.

In its nature, religious education works slowly, in an evolutionary manner. It creates no sudden perfect world. It offers no magic solution to problem. It gives no categorical promises. It demands effort and discipline from its adherents. It awakens man to his own creative 
possibilities. Education in religion, when rightly considered, is man's most formidable tool for survival (Ilori, 2013) because it can transform pupils' assessment of themselves et al, and their understanding of the broader position of the planet. It is the rationale why education is targeted at encouraging tolerance and respect for others. The education that has the potential to do that is religious education. Religious education teaches about religion in its broadest sense and about religious diversity.

Religious education may be a programme for studying about religion in many forms, as a crucial dimension of human experience and a big disciple within the school curriculum (Engeberton, de Souza, Durka \& Gearon 2010). It pursues a balanced approach to teaching and learning about religion. It provides opportunity for both a deeper sense of self-realization and a broader civil acceptance of others. It balances the familiar and therefore the foreign in ways in which give individuals new insight into both. Religious education can facilitate the development of both empathetic appreciation and important analysis (Engeberton et al 2010). It teaches the individual about a world of religious diversity, but at the same time it encourages one to think in terms of national unity.

Religious education has a way of broadening the learner's way of thinking and instilling self-confidence. It provides moral guidance and encourages people to improve their lives. In religious education lessons, pupils learn to become more broadminded, to accept other people's beliefs and faiths and not to let race or religion come in the way of what potentials they see in private.

\subsection{Development}

As an idea, different definitions exist. Development may be a multidimensional phenomenon which may be seen from many points of view by different authors. Development was first seen in terms of socio-economic growth only but during this time we live in, it includes man, environment, material also as infrastructure.

Development as pointed by Ozioma (2017) may be a process of improving the standard of all human lives with three equally important aspects. These are: i). raising people's living levels in terms of incomes and consumption, food, medical services, education through relevant growth processes. ii). Creating conditions conducive for the expansion of peoples, self-esteem through the establishment of social, political and economic systems and institutions which promote human dignity and respect. iii). Increasing people's freedom to choose by enlarging the range of their choice variables, e.g. sorts of goods.

Ejizu (2008) likened the event thereto that of an animate organism, using the analogy of living organism (man). Omoregbe (2000) affirms that the foremost important aspect within the development of a person's person is his moral development. This is often particularly true because the scholar argues that the "moral development of citizens must precede other aspect of the event otherwise the method of development would be obstructed by the immorality of the citizens.

Falade (2015) rightly acknowledged that education which may be a lifelong process may be a tool for human moral development. The education that's known to be competent of ethical development should be religious education that's wholistic in nature and application. Development may be a continuous process of positive change within the quality and span of lifetime of an individual or group of persons. Religious education is capable of manufacturing a private who can become a change agent that sustainable development requires. With religious education that wholistic, 21 st century Africa are able to do the event that meets the 
requirements of this without compromising the power of future generations to satisfy their own needs.

\section{Discussion}

\subsection{What is Wholistic Education?}

Wholistic education may be a relatively new movement in education that seeks to interact all aspects of the learner, including mind, body, and spirit (Ronghuai, Spector \& Michael, 2012). Its philosophy, which is additionally identified as wholistic learning theory, is predicated on the premise that every person finds identity, meaning and purpose in life through connections to their area people, to the wildlife, and to humanitarian values like compassion and peace (Johnson, 2019).

Wholistic education may be a clear departure from the knowledge transmission approach to education that we have been conversant in within the UBE curriculum. Wholistic education prepares a student for lifelong learning during which the tutorial focus moves towards the life skills, attitudes and private awareness that the scholar will need in an increasingly complex world. Wholistic education also called wholistic learning is an approach to education that involves educating a toddler in order that they're going to become all rounded and assured adult who contributes in effective development of his community.

Marshman (2010) defined wholistic education as education which focuses on the fullest possible development of the person, encouraging individuals to become the absolute best that they will be and enabling them to experience all they will from life and reach their goal. consistent with Zamroni (2014) wholistic education may be a process of learners' culture cultivation which is multilevel (cognitive, emotional, social, physical, artistic, creative and spiritual). To Miller (2015) it's an education which develops all learners' potential harmoniously (integrated and balanced), which are intellectual, emotional, physical, social, aesthetic, and spiritual. These six aspects are developed consonant, one potential shouldn't grow far beyond the power of the opposite aspects, because it may result in human who isn't wholistic.

The problem of stunted development we are experiencing today in Nigeria and it is affecting the implementation of UBE programme can be regarded as lack of religious values in the behaviour of the citizens and the inability to create a representative religious culture. The problem is an academic problem that needs to be criticized and solved by educational institutions through transforming not only the students' achievement academic quality, moral toughness and social sensitivity. To realize wholistic knowledge in people, the theory and reality of life, from books and from society should not be separated (Zamroni, 2014).

Wholistic education focuses on the entire person rather than one or some segments of a person's experience. It formed a part of the view that the planet may be a single whole which learning can't be separated from all of man's experiences.

Since any approach to education must ask itself, what's the goal of education? Wholistic education aims at helping students be the foremost that they will be. Abraham Maslow referred to this as "self-actualization". Education with a wholistic perspective cares with the event of each person's intellectual, emotional, social, physical, artistic, creative and spiritual potentials. It seeks to interact students within the teaching/learning process and encourages personal and collective responsibility. 


\subsection{Wholistic Education Curriculum}

An application of wholistic education in UBE curriculum can be described as transformational learning where the instruction recognizes the wholeness of the learner which he and therefore the curriculum is not seen as separate but connected (John, Kelli, Marni, Bruce \& Crowell, 2018). A wholistic curriculum is a curriculum that uses the basic ideas of wholistic learning to teach people. According to John Miller, the position is analogous to the Quaker belief that there's "that of God in everyone".

In wholistic education the essential three R's are said to be education for: Relationships, Responsibility and Reverence for all life. First, children need to learn about themselves. This involves learning self-respect and self-esteem. Second, children need to learn about relationships. In learning about their relationships with others, there's attention on social "literacy" (learning to ascertain social influence) and emotional "literacy" (one's own self in reference to others).

Third, children need to learn about resilience. This entails overcoming difficulties, facing challenges and learning the way to ensure long-term success. Fourth, children need to learn about aesthetics - This encourages the student to see the beauty of what is around them and learn to have amazement in life.

\subsection{Techniques of Teaching Wholistic Education in UBE}

With the goal of teaching the entire child, wholistic education promotes several strategies to deal with the question of the way to teach and the way people learn.

First, transformative approach to learning. Rather than seeing education as a process of transmission and transaction, transformative learning involves a change within the frames of reference that an individual may need. This change includes teaching students to reflect critically on how we come to understand or understand information. As a result, if "we ask students to develop critical and reflective thinking skills and encourage them to worry about the planet around them they'll decide that some degree of personal or social transformation is required."

Second, the thought of connections is emphasized as against the fragmentation that's often seen in mainstream education. This fragmentation may include the dividing of individual subjects, dividing students into grades, etc. Holism sees the varied aspects of life and living as integrated and connected, therefore, education shouldn't isolate learning into several different components.

Third, along the same thread as the idea of connections, is the concept of transdisciplinary inquiry. Transdisciplinary inquiry is predicated on the premise that division between disciplines is eliminated. One must understand the planet in wholes the maximum amount as possible and not in fragmented parts. Fourth, meaningfulness is additionally a crucial think about the training process. People learn better when what's being learned is vital to them. Holistic schools seek to respect and work with the meaning structures of every person. Therefore, the beginning of a subject would begin with what a student may know or understand from their worldview, what has aiming to them instead of what others feel should be meaningful to them.

Fifth, community is an integral aspect in holistic education. As relationships and learning about relationships are keys to understanding ourselves, therefore the aspect of community is significant during this learning process. Scott Forbes stated, "In holistic 
education the classroom is usually seen as a community, which is within the larger community of the varsity, which is within the larger community of the village, town, or city, and which is, by extension, within the larger community of humanity."

\subsection{Importance of Wholistic Education in UBE Curriculum}

A wholistic approach to education believes:

1. Education is about educating the whole child.

2. Teachers must guide the student to become happy and well-rounded adults.

3. Teach students that they are interconnected with the world around them.

\subsection{Problems of Wholistic Education}

1. Underemphasizing of academic learning. It limits children's time on academic aspects of learning. The world is in the era of maths and science.

2. It is not much used beyond early years of schooling.

3. It is time consuming and expensive e.g. sending children to camps, sports, making art work etc.

4. It doesn't fit well with many school curriculum. Many schools have very strict learning outcomes. Very crowded with maths and sciences as important subjects.

\subsection{Religion, Development and Wholistic Education}

From the beginning, this paper has pointed out religion as the major problem hindering sustainable development in 21st century. As complex as the problem of religion is, it has to be observed that it is largely perpetrated by human beings. What this means is that the world has human problems despite its enormous natural and human resources. The change of the human person therefore, becomes a contemporary issue and challenge in African development patterns. Change here, must not be seen in the context of political, economic, social or in government policies only. Change is a complex-whole which comes from within a person and that it must be based on ethical principles. This is the kind of change that this paper proposes.

When the human person is changed from within, every other thing around him/her will change naturally. Achebe (1984) had pointed out before now, that "the trouble with Nigeria is simply and squarely a failure of leadership". This presupposes change. But, as true as Achebe's assertion is, leadership in Nigeria has changed hands severally with little observable change seen in the society. Today, the problem of the world is no longer that of leadership only. The problem is not only poverty, religion, failed infrastructures, bad roads etc but human problem. If a person is morally developed, the world would definitely develop. The primary gap in development is fearless moral leadership. It is religious education that can form this attribute into the human person. This is possible, through wholistic education.

In many primal cultures, religion is still and that the organizing principle of life. It was not called "religion" as such since it did not belong to a separate realm one could distance oneself from or reflect on objectively. Religion was the assumption and knowledge system around which all reality was organized.

Wholistic education is an effort to improve the education quality in schools. The actualization of wholistic education is closely linked to the religious conditioning being established among the school's members. The achievement of wholistic education requires efforts to change the conditions and behaviors of school, school community, and school supporters, thus the school's cultural dimension becomes very central. It is a known fact that religious education actively promotes values of truth, justice, respect for all and care of the 
environment. It places specific emphasis on pupils valuing themselves et al. For instance, it is through religious education that the individual learns that he has specific obligation to himself, to his fellow human beings and to the society to which he belongs. It moulds the human character and life in a way that enables the individual and the society at large to experience growth and development. However, from the perspective of religious education, human being has a spiritual nature which is the source of such motivation as showing love, seeking truth and desiring to serve others.

Consequently, if one were to approach development from a religious perspective, one will uphold the values of cooperation, concern for others rather than competition and pursuit of self-interest. Religion brings order in the society. A well-ordered society provides serene atmosphere for development to thrive. Durkheim in Ozioma (2017) affirms that where there is religion in practice, morality abounds and this becomes the source of security for the members of that society. The means of development of spiritual insights in these youths is through religious education. Religious education brings order in human society by placing specific emphasis on the role of family and the community in religious belief and activity. Through the promotion of self-worth, religious education can produce fearless moral leadership during this 21st century Africa. As soon as this is done, religious education has successfully, succeeded in filling the primary gap in development.

\section{Conclusion}

If there should be sustainable development in the 21st century, it is important for UBE to look in the direction of religion as base for wholistic education and nation's development. This is because religion is a change agent. This change is possible because it is worthwhile and transformative. No known religion is barren of moral and ethical principles. Indeed, religion may be a force which has mostly influenced the character of mankind. Man's ethical standards, his moral behaviours and standard of judgment appears to be products of his religious training. This implies that a wholistic religious education is a step in the right direction. This paper thus maintains that development can be enriched by the insights offered by religion, faith, spirituality and values. Wholistic education implementation in UBE curriculum programme is an approach that can meet the needs of all types of development. It is compatible with both global education and environmental education, which also supported the principles of interdependence and connectedness.

\section{Recommendations for Practice in UBE}

Based on this interdependent perspective, wholistic education seeks to create a society where we live in harmony with the surrounding environment. The paper recommended that: (1) Religions should be carried along in making policies to always inculcate moral principles, justice, truth, equity and honesty which is a reagent to personality change thereby reduce religion. (2) The study of moral education should be made compulsory in all categories of learning and national orientation agency should also include it in their plans. (3) Servicelearning courses and community engagement initiatives in which students can connect to and further explore their spirituality should be encouraged. These types of services engage students with their peers and their communities, exposing students to various types of people and environments, while allowing them to exercise their beliefs of modeling the way. (4) School curriculum should be more of reflective thinking. Reflection is an important way that students can actively invest in crafting, understanding, owning, and expressing by which their sense of self, fundamental values, motivating commitments, and dispositions to action are bound together in a unified whole. 


\section{References}

Achebe, C. (1984). The trouble with Nigeria. London: Heinemann.

Aja, S. N., Eze, P. I. \& Eke, N. (2014). Over view of the progress and challenges of education for all in Nigeria. Educational Research, 5(7): 257 - 260.

Ozioma, R. (2017). Religion and development in the 21 st century Africa. Journal of Humanities and Social Science, 1(3): 63-67.

Ejizu, C. I. (2008). Between religion and morality: Their inter-connection and significance in public life". A University of Port Harcourt Inaugural lecture (Inaugural lecture series) no.59. March, 13.

Engebretson, K., de Souza, M., Durka, G., \& Gearon, L. (Eds.) (2001). International handbook of inter-religious education Part 1. London: Springer Dordrecht Heidelberg.

Falade, D. A. (2015). Christian religious knowledge and the teaching of moral values in the Nigeria

Junior Secondary Schools: Problems and prospects. American International Journal of Research in Humanities, Arts and Social Sciences 9(2): 148-151.

Forbes, S. H. (1996). Values in holistic education. Paper presented at the Third Annual Conference on Education, Spirituality and the Whole Child (Roehampton Institute, London, Pg. 9.

Huang, Ronghuai, H., Spector, K. \& Michael, J. (2012). Reshaping learning: frontiers of learning technology in a global context. Heidelberg: Springer Science \& Business Media. p. 367. ISBN 978-3-642-32300-3.

Ikechi-Ekpendu, C., Audu, S. D. \& Ekpendu, I. C. (2016). An Evaluation of the Role of Religion

in the Development of Nigeria. Developing Countries Studies, 6(10): $82-87$.

Ilori, A. J. (2013). Philosophy of Christian education: An African perspective. Plateau: African Christian Textbooks.

Igwe, R. O., Rufai, S. A., \&Olufemi, A. G. (2013). Social reconstruction through religious education: A survey on Nigeria. Humanities and Social Science Journal 8(1): 10-18

John P. M. et al, (2018). International handbook of holistic education. Oxon: Routledge

Johnson, Andrew P. (2019). Essential learning theories: applications to authentic teaching situations. Lanham, MD: Rowman \& Littlefield. p. 120.

Marshman, R. (2010). Concurrency of learning in the IB Diploma programme and middle years programme. Retrieved from https://kirrawatt.com/uploads/2/4/7/2/247249/holistic_education.pdf on $8 / 11 / 2020$.

Obasanjo, O. (2000). President Olusegun Obasanjo "s Speech at the Inauguration of the Independent Corrupt Practices and other related offences Commission (ICPC)". September

29.

Omoregbe, J. I. (2000). Ethics, a systematic and historical study. Lagos: Jajo Educational Research and Publishers.

Stephen D. B., Jan, R. G. \& Glenda, C. (2015). Why Do Policies Fail in Nigeria? Journal of Education and Social Policy, 2(5): $10-21$. 